\title{
Approach to simulation assessment of area-wide traffic calming in the context of sustainable development
}

\author{
A. Książek \\ Department of Transportation Systems, \\ Cracow University of Technology, Poland
}

\begin{abstract}
The introduction of traffic calming in city centre areas is one of the measures aimed at implementing the transport policy which is based on the principles of sustainable development. Traffic calming refers to a combination of road network planning and engineering measures to reduce negative effects of motor vehicle use and improve conditions for non-motorized street users. However, it should not be seen exclusively as a means of introducing traffic restrictions or reducing the speed limit. Comprehensive schemes of area-wide traffic calming result in a synergy effect improving not only traffic conditions but also liveability, environment, safety and the urban landscape. However, one has to emphasize that what is crucial for making use of the capabilities of a comprehensive traffic calming scheme is the proper preparation of the investment. Implementing the ideas of traffic calming should bring the best results in enhancing sustainable safety of drivers and pedestrians, improving the quality of urban life and reducing traffic flows and undesirable effects, such as traffic noise and pollutant emissions. The paper contains a literature review on impacts and effectiveness of area-wide traffic calming solutions. An exemplary approach illustrating how to include traffic calming zones in simulation modelling is also presented. The suggested approach involves the use of simulation tools in both micro and macro scale and tests with a driving simulator to assess the influence of traffic calming measures on speeds, travel times, route choices, modal split and therefore on the level of road safety, traffic noise and air pollution. The influence of individual measures examined at a microscopic level allows one to assess the functioning of the whole transport system at the macro level. This makes it possible to plan the transport service of the area, to reduce
\end{abstract}


congestion and migration of disruptions onto other network links as well as to prepare a proper assessment of functional effectiveness of implemented solutions.

Keywords: traffic calming, sustainable transportation, traffic modelling, urban traffic, driving simulator

\section{Introduction}

Strategies targeted on implementing sustainable development solutions put a substantial emphasis on urban transport policies. Sustainable transportation comes with a decrease of private vehicles share in modal split. Other ways of travelling are preferred, like walking, cycling or using public transport. Changing the inhabitants' behaviour is achieved by promoting eco-friendly means of transport and implementing restrictions for private cars in certain areas of the cities. A crucial area is the city centre, where the measures of restricting access are concentrating. Constraints like closures, one way streets, congestion charging, parking pricing etc. are introduced to assure a lower use of private vehicles. A way of restraining undesired behaviours and promoting a more preferable land-use is traffic calming. However, as it is pointed out in a definition by the Institute of Transportation Engineers [1]: Traffic calming is the combination of mainly physical measures that reduce the negative effects of motor vehicle use, alter driver behaviour and improve conditions for nonmotorized street users. As such, traffic calming solutions can result in increase of liveability, reduction of noise and air pollution as well as improvement of road safety and urban landscape.

The effects of traffic calming depend on the spatial scale of implemented solutions. O'Brien [2] defines three scales of influences:

- Level I - local scale, where traffic volumes and capacities are not important.

- Level II - actions to restrain traffic impacts at a corridor, where traffic conditions are important but only inside the corridor, not really at the network level.

- Level III - actions at macro-level where restraints are introduced in a greater area and traffic volumes, capacities and levels of service are important in a city-wide scale.

Area wide traffic calming zones designed comprehensively are an important part of a sustainable transportation toolbox. Moreover, it is not only about transportation, but by altering the safety of drivers and pedestrians, enhancing liveability, improving air quality, changing social behaviours and promoting walkability, it is a great way of creating a sustainable city.

\section{Implementing traffic calming zones}

A key issue in introducing traffic calming strategies is the planning process. Implementation of designed solutions should be preceded with a detailed 
prognosis of possible effects on road safety, traffic volumes and environmental and social issues. Adjusting the capacity of a through road and preventing accidents occurrence is important in the aforementioned second level of spatial scale of calming the traffic. But the most detailed analysis should be done in a third scale, for comprehensive area-wide schemes.

Traffic safety analysis begins with the effectiveness of speed reduction and driver behaviour changes for particular traffic calming measures. There are numerous studies on "before and after" data of impacts on accident reduction. However, one has to emphasize that analyses should be done in a greater scale to find the real impact of area-wide solutions. Grana et al. [3] reminded that traffic volumes, as well as threats for street users, may shift onto other streets. The accident rate per kilometre travelled may increase, which should be predicted. In the same paper, as well as in [4], the authors describe a procedure for implementing traffic calming zones which allows forecasting possible changes in urban sustainable safety. Traffic calming strategies are included in the concept of sustainable safety, which according to SWOV [5] should provide an infrastructure design which drastically reduces crash risk, especially excluding the possibilities of severe injuries. A detailed analysis of the safety effects of area-wide calming schemes was also conducted by Elvik [6]. Estimations of future impacts in a macro scale are being prepared, as it was shown by Lord and Persau [7] and Lovegrove and Sayed [8].

Luoma and Sivak [9] highlighted in their study that for sustainable road transportation it is substantial that introduced solutions would cover two important issues. Implemented measures should bring double benefits improving both road safety and the environment. The study examined interactions of environmental and safety measures for road transportation. In conclusion, areawide traffic calming was found, among few others, to support both policy objectives. Sometimes, traffic calming may cause a slight increase of fuel consumption or emissions but it is a matter of proper design. These environmental impacts can be forecasted using appropriate software. Energy consumption and emissions are connected with traffic volumes and driving performance of vehicles. And those can be forecasted with traffic modelling.

It is crucial to know what flows may occur on streets included in a traffic calming scheme. Many guidelines (e.g. [10-12]) include stipulations on what kind of measures can be introduced depending on street function and the magnitude of traffic flows. Apart from that, it is natural that area-wide solutions will bring changes in traffic volumes in a large part of the city. Alterations of routing decisions, modal split and travel demand may occur after implementing a comprehensive traffic calming scheme. Problems with congestion, traffic disruptions might migrate onto other parts of a street network and this should be forecasted.

\section{Traffic calming solutions in trip modelling}

Basic tool for assessing the network-wide effects of traffic changes are the macroscopic simulation models. They enable a forecast of the effect of 
infrastructural development on the performance of transport system. Such elements as street closures, one way streets or diverters are easily represented in macrosimulation models. Ewing [13] points out that the statistical analysis and "before and after" studies are insufficient for a proper prognosis of possible future impacts of restrictions caused by traffic calming. The publication contains also the data on the effects of various measures on traffic flows. A natural impact comes from volume control measures such as full or half closures, intersection diverters, median barriers etc. And these restrictions are of course very simple to insert in a supply part of our macroscopic model. As for speed control measures, they affect the travel time. Vertical and horizontal measures influence the speed choices of drivers forcing them to slow down. As a result, drivers experience delays while crossing speed humps, speed cushions, narrowings, chicanes etc. Hence, using travel times in traffic assignment and modal split procedures in classic four-step models allows an assessment of traffic calming measures in a network scale. First attempts carried out by the author have already been described in [14] where PTV VISUM software was used for assessment of areawide traffic calming. Three different scenarios of traffic calming applied in the centre of Bielsko-Biała, a city in southern Poland, were analysed within a longterm forecast. The scenarios varied in the level of restrictiveness of proposed solutions. Speed humps, cushions, tables and raised intersections, as well as some volume control measures, were included in these schemes. Simulation analysis was preceded by field experiments of the delay times on such speed control measures in comparable conditions. This enabled the representation of measures in the model and getting the results of total vehicle kilometres travelled and flows differences between the scenarios and finally, suggesting the best version of the design to apply in real conditions.
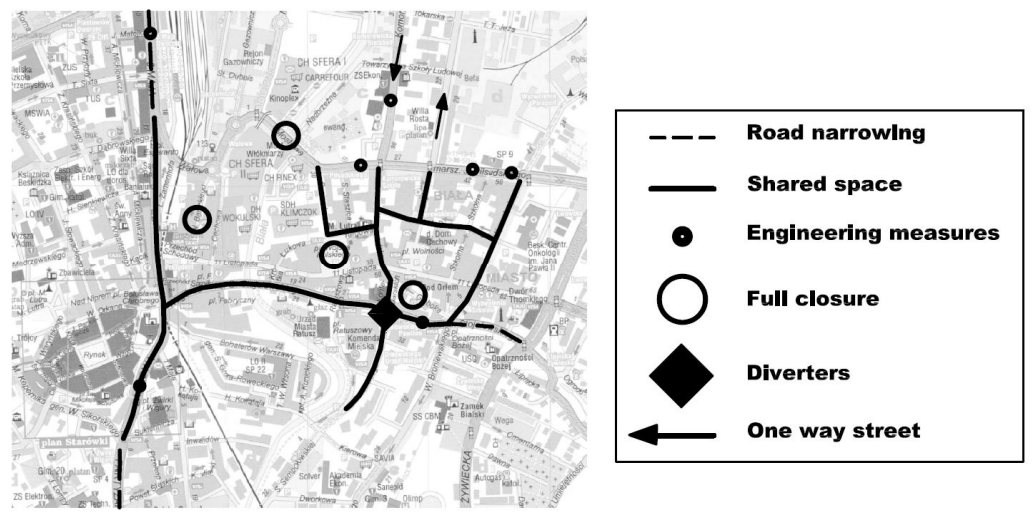

Figure 1: One of the traffic calming scheme scenarios simulated by the author. (Source: [14].)

Extension of travel times was used to represent engineering measures of traffic calming also by Mao and Koorey [15], Gardes [16] and Rose et al. [17]. A 
paper by Mao and Koorey [15] covered a study of a large spectrum of calming measures containing chicanes, closures and vertical deflections. Road network with the designed elements was modelled in TrafikPlan software. Simulation results were then compared with the ones observed in real conditions. Gardes [16] described a comparative study of two alternative roads using Paramics software. One of them consisted of elements of traffic calming, while the other included some capacity improvements. Simulation model was used to examine routing decisions affecting observable traffic flows on both roads. Rose et al. [17] compared two different simulation programs: CONTRAM and TrafikPlan as a tool for traffic calming schemes assessment. In both programs vertical engineering measures were included and the parameters of street networks functioning were collected. Studies with various calming measures and various level of demand scenarios showed a significant reduction of "rat running" behaviours. In the same paper the authors mention the research which shows that drivers perceive a time loss due to traffic calming measures presence as longer than the real observed one. This may also affect route choices or even travel demand. Also Crane [18] writes about the perception of applied restrictions. He brought into comparison three design elements (grid street network, traffic calming, mixed land uses) and found that only the traffic calming elements may reduce the number of individual trips.

Presented examples indicate that representation of area-wide traffic calming in macrosimulation models may be a very desirable step. Intended studies will allow the assessment of traffic calming schemes in the context of urban transport system functioning with respect to the impact on modal split, routing decisions and in result, on observable traffic flows. Aforementioned analyses of network effects show, that in order to properly represent the impact of engineering measures, detailed examination of speeds and travel times alterations for each type of measure are essential.

\section{Influences of individual traffic calming measures}

Studies on impacts of various traffic calming measures on driving speeds are widely present in the literature. Mean speeds and 85 percentiles are most often chosen as an evaluation parameter to compare them with the situation before introducing traffic calming elements. For various engineering measures studies of travel times and driving behaviours are carried out. As an example, Johnson and Nedzesky [19] examined the behaviours at speed humps, speed slots and speed cushions. A broad set of data on effects of speed cushions can be found also in a paper by Layfield and Parry [20]. A greater number of measures, including intersection narrowings were described by Cynecki and Huang [21]. Travel times are important also for emergency vehicles, so such effects were examined e.g. by Batson [22] and Coleman [23] where data for various measures and various emergency vehicles are collected. Along with environmental issues this highlight that it is a key thing to design a traffic calming scheme in such a way that we force drivers to drive with a desired speed and with a possibly smooth speed profile. As for that, it is important to quote Figure 2 which shows a 
speed profile along a calmed street. What is essential for a sufficient adjustment of speed to the limits is a proper selection of calming elements and spacing between them.

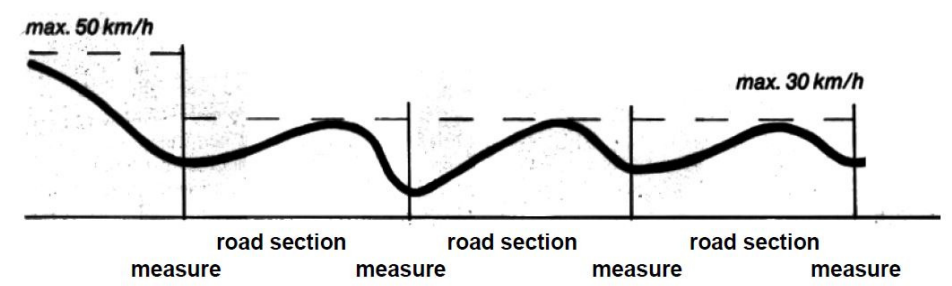

Figure 2: Desired speed behaviour for $30 \mathrm{~km} / \mathrm{h}$ zones. (Source: [24].)

The impact of various traffic calming measures and distances between them was examined by García et al. [25]. Field experiments using GPS tracking were carried out to derive speed profiles on existing, calmed streets. The profiles were then used to calibrate and validate a microsimulation model where various types of measures and spacing between them were simulated. Adjusting the level of demand in the scenarios served to assess the capacities of sections with installed calming devices. Precisely determined speed profiles allow adjusting driving behaviours in a calmed area, while the calculated capacities enable an efficient plan of traffic calming scheme and a representation of elements in macrosimulation models.

An analytical approach was shown by Barbosa et al. [26] where a mathematical model was prepared to calculate the speed profile. A formula was developed to determine the speed of a vehicle in every spot along a calmed road as a function of entry speed, distances from and to consecutive measure and the type of applied measure. For each device also the range of its influence on driving speeds was calculated.

Another application of field experiments was shown by García and Moreno in [27] where speed profiles on calmed streets were examined for traffic safety analysis. It was also pointed out that the capacities of traffic calming solutions should be adjusted to forecasted traffic flows on through roads crossing small communities and that there is a necessity to evaluate traffic calming considering the consistency of a speed profile. The studies enabled to determine the optimal spacing of devices in respect to road safety.

Described research convinces us to use GPS tracking for determining speed profiles to evaluate traffic calming measures. Collecting profiles in real conditions helps to assess thoroughly the impact of individual elements. Planned experiments conducted on a wide range of engineering measures will help to set a general relationship between the occurrence of traffic calming devices and characteristics of driving behaviour. 


\section{Emission models}

Another argument for reducing frequent and sharp acceleration and deceleration manoeuvres is the matter of acoustics and pollutant emission. It was pointed out by Bohatkiewicz et al. [28] in the context of preventing an excessive noise. Placing the elements of traffic calming may result in numerous breaking and accelerating behaviours from drivers. However it does not comply with what calming the traffic should result in, which is a safe, relatively slow and monotonous drive along the whole street. In the paper the authors added an example of acoustic analysis including a forecast of noise spreading. The study involved a range of engineering measures such as speed cushions, chicanes and roundabouts on a street connecting two estates in Krakow.

Ahn and Rakha [29] examined the impact of driving through traffic calmed area on emission rates and fuel consumption. Speed profiles were collected for speed humps and traffic circles to characterize driver behaviour. Then, using microscopic emission model, energy impacts were calculated. Studies showed that fuel consumption and gas emissions may increase after implementing traffic calming solutions, especially when drivers prefer a more aggressive way of driving. Analyses of air quality and energy impacts of traffic calming implementation were also conducted by Ainge et al. [30] and Ghafghazi and Hatzopoulou [31]. The latter contains also an evaluation in a greater than micro scale. Effects of designed traffic calming scenarios were tested within a calmed section and in the level of whole area-wide neighbourhood. This approach, which includes network effects, distinguishes the research from others focused on emission calculations. To determine the influence on rerouting, OD matrices for analysed area were prepared and a model was created in a scale that one can describe as mesoscopic. From a metropolitan model of Montreal data on trips crossing the calmed area were derived. This area was inserted in microsimulation software PTV VISSIM. Traffic assignment was carried out using the DTA function (Dynamic Traffic Assignment). The scale and assignment used allowed a precise representation of the restrictions effects coming from traffic calming. However it resulted in a substantial burden for computing power, where each scenario took long hours to simulate traffic and calculate the emissions. Impacts of each device were represented as speed reduction areas. The value of reduction and the length of area were assumed by authors without any additional studies. Results of the simulation were then used in an emission model for assessing the changes in air pollution. As parameters for evaluating the scenarios authors chose: total number of vehicle kilometres travelled within the network, total vehicle emissions and emission percentage change on each link. The research showed a little increase of air pollutant emissions and a lower number of total vehicle kilometres travelled.

In order to increase the reliability of aforementioned studies, the research on detailed effect of traffic calming measures should be carried out. Such procedure was described by Lee et al. [32]. Data on speed profiles for chicanes, speed humps and speed tables were collected using test drives with GPS trackers. Those profiles were compared with data taken from PTV VISSIM where speed 
reduction areas were inserted. In such way, it was possible to verify the length of the areas and value of speed reductions to apply. After such prerequisites further emissions calculations were more precise. Authors found that chicanes are the best way to calm the traffic in order not to increase the environmental threat too much.

The intended framework for examining traffic calming effects include determining real speed profiles collected through field experiments with GPS tracking. This enables to check the impacts of traffic calming on drivers behaviour and a proper representation of calming solutions in a micro scale. It may also serve in enhancing the functionality of microsimulation software with a possibility to automatically insert engineering calming measures with specific parameters, adjustable to local conditions. With a proper calibration of micro model it is possible to achieve credible results defining the parameters of traffic on a calmed street or a calmed neighbourhood and export them into a macro scale.

\section{The use of a driving simulator}

Field experiments to examine traffic calming measures are time-consuming and expensive. This as well as the vast diversity of many possible calming solutions may induce the use of driving simulator to assess the impact of various measures on driving behaviour. Driving simulators are yet of great interest in many academic and research centres across the globe. They allow to exam driving parameters, drivers' behaviours and infrastructural impacts under controlled environmental and traffic conditions without any disturbing factors. Bella [33] lists the advantages of using driving simulator, like efficiency, low cost, safety of the experiment, full control over all conditions and the ease of data collection. He also remarks the necessity of a proper verification of simulator's functioning in comparison with the field studies.

In the current literature one can find many descriptions of using driving simulator to evaluate the impact of infrastructural and environmental changes on speed choices and behaviour of drivers. Antonson et al. [34] and Bergeron and Thiffault [35] were examining the effects of landscape changes on the driver. The effect of on-street parking in urban environment was tested by Edquist et al. [36]. Charlton [37] describes various scenarios of horizontal curves marking, while Auberlet et al. [38] checked speeds and steering of vehicles on vertical curves.

Various scenarios of road marking could consist of traffic calming elements. Hence, simulator is being used for the assessment of gate elements on through roads entering urban communities what was included by Ariën et al. [39] and [40]. In [39] parameters were also used to describe the changes of steering behaviour. Apart from the standard speed profiles, standard deviation of longitudinal acceleration and deceleration and standard deviation of lateral position were introduced. In another publication, by Galante et al. [41] not only gate construction but also various scenarios of road marking and changes of road curvature are described. Moreover, authors are planning to implement proposed 
solutions and compare the results from the driving simulator with those collected in field after building the designed elements. Montella et al. [42] published also an extended research results with greater set of measures. Also Montella et al. in [43] and [44] used the driving simulator for examining other solutions, on road links near intersections. Various scenarios of signing, road surface changes, median strips and refuge islands were introduced in the research. The results consist of the comparison of speed profiles and analysis of variability of vehicle's position on the road.

Molino et al. [45] used the driving simulator in a more broad scope, separately in the analysis of road safety on curves, as well as on chicanes and road narrowings near intersections which are applied in traffic calming of urban streets. A very broad range of traffic calming measures in the form of medians as well as horizontal and vertical signing were examined with the University of Leeds simulator by Jamson et al. [46]. Report by Corkle et al. [47] which describes the effectiveness of traffic calming strategies on speed and flow reductions contains a great number of data on the impact of traffic calming measures defined with field experiments and in comparison with simulator studies. Confrontation of these results demonstrated a substantial compatibility and shows the advantages of using driving simulator. It enables to obtain a great set of parameters and results with lower variability. Examined scenarios consisted of elements such as narrowings, median strips, islands and modification of road marking. Due to the limitations of used simulator there was no possibility to check the effects of vertical measures which affect the speed choice by their convexity. However, modern simulators, with proper software, placed on independent, movable platforms, carry a hope to properly examine vertical deflections, such as e.g. humps or cushions.

The possibility of using driving simulator allow to research various traffic calming measures, all in identical conditions in a fully controlled environment. Available software may collect all parameters essential for describing the changes in driver behaviour on individual traffic calming measure and while driving inside an area-wide traffic calming scheme. Impacts from all these measures should be used as factors in calibrating simulation models for the purpose of proper representation of traffic calming in trip modelling.

\section{Conclusions}

Presented literature studies on assessment of traffic calming measures and schemes lead to formulate assumptions for research necessary to represent these solutions in trip modelling. Examples of analyses of existing area-wide traffic calming implementations show a significant diversity in traffic flows variance resulting from these applications. In order to make a reliable forecast of the impact on urban transport system performance it is essential to include traffic calming in macrosimulation models. A proper representation of measures is possible only after detailed studies in a lesser scale. A great diversity of elements result in a substantial variance of effects described in numerous researches. Hence, the experiments should be conducted on a possibly broad range of 
measures. The most sufficient and reliable would be a combination of field experiments and driving simulator usage. It will assure avoiding the limitations of the simulator as well as validating obtained results. Studies at this level will enable including traffic calming in a micro scale.

Planning the design of a scheme should consist of adjusting the capacities and traffic conditions of implemented solutions to values desired by the engineer. Parameters of links, intersections and the calmed network are indispensable for creating a macrosimulation model. In such scale, it is possible to determine the impact on modal split, routing and as a result on traffic volumes in the area and in a greater range of the city street network. Creating a comprehensive framework for simulation assessment of area-wide traffic calming will improve a process of planning and implementing traffic calming allowing forecasting the impact on traffic flows, road safety, and transportation induced noise and emissions. It might help in avoiding potential negative effects of accidents and flows migrations or air pollution increase.

\section{References}

[1] Lockwood I.M., "ITE Traffic Calming Definition”, ITE Journal, Vol. 67, 1997.

[2] O'Brien A., Traffic Calming - Ideas Into Practice, ITE Publication p. 37, Washington DC 1993.

[3] Grana A., Giuffre T., Guerrieri M., Benefits of area-wide traffic calming measures: outcomes still to assess, The Sustainable City V: Urban Regeneration and Sustainability, WIT Transactions on Ecology and the Environment 2008.

[4] Grana A., Giuffre T., Guerrieri M., Exploring Effects of Area-Wide Traffic Calming Measures on Urban Road Sustainable Safety, Journal of Sustainable Development Vol. 3, No. 4, 2010.

[5] SWOV, Advancing Sustainable Safety, National Road Safety Outlook, SWOV Institute for Road Safety Research 2006.

[6] Elvik R., Area-wide urban traffic calming schemes: a meta-analysis of safety effects, Accident analysis \& prevention 2001.

[7] Lord D., Persau B. N., Estimating the safety performance of urban road transportation networks, Accident analysis \& prevention 2006.

[8] Lovegrove G. R., Sayed T., Using macro-level collision prediction models in road safety planning applications, TRB Annual Meeting 2006.

[9] Luoma J., Sivak M., Interactions of environmental and safety measures for sustainable road transportation, European Transport Research Review Vol. 4, Issue 42012.

[10] Road Directorate, Denmark Ministry of Transport, An Improved Traffic Environment Catalogue of Ideas, Road Data Laboratory Road Standards Division, Report 106, 1993.

[11] CROW, Recommendations for traffic provisions in built-up areas ASVV 1998. 
[12] Mazur H., Lauenstein D. et al., Erfahrungen mit Tempo 30 Umwelt Bundes Amt, 1996.

[13] Ewing R., Traffic Calming: State of the Practice, ITE Publication no. IR098, Washington DC 1999.

[14] Książek A., Analysis of zonal traffic calming solutions, Transport Miejski i Regionalny $1 / 2013$.

[15] Mao J., Koorey G., Investigating and modelling the effects of traffic calming devices, IPENZ Transportation Conference Christchurch, 2010.

[16] Gardes Y., Evaluating Traffic Calming and Capacity Improvements on the SR 20 Corridor Using Microscopic Simulation, TRB Annual Meeting 2006.

[17] Rose G., Brownbridge N., Hills P. J., Modelling the effects of traffic calming schemes, tec 2001.

[18] Crane R., On Form versus Function: Will the New urbanizm reduce Traffic, Or Increase It?, Journal of Planning Education and Research, Vol. 15,1996 ,

[19] Johnson L., Nedzesky A. J., A Comparative Study of Speed Humps, Speed Slots and Speed Cushions, ITE 2008.

[20] Layfield R. E., Parry D. I., Traffic calming - speed cushion schemes, TRL Report 312, 1998.

[21] Cynecki M. J., Huang H. F., The Effects of Traffic Calming Measures on Pedestrian and Motorist Behavior, FHWA Report RD-00-104, 2001.

[22] Batson S., Offset Speed Tables for Reduced Emergency Response Delay, ITE Technical Conference, 2004.

[23] Coleman M. A., The Influence of Traffic Calming Devices upon Fire Vehicle Travel Times, Portland Department of Transportation.

[24] van Schagen I., Traffic calming schemes, Report R-2003-22 SWOV, 2003.

[25] García A., Moreno A. T., Romero M. A., Torres A. J., Traffic Microsimulation Study to Evaluate the Effect of Type and Spacing of Traffic Calming Devices on Capacity, Procedia - Social and Behavioral Sciences, Vol. 16, 2011.

[26] Barbosa H. M., May A. D., Tight M. R., A model of speed profiles for traffic calmed roads, Transport Research Part A 34, 2000.

[27] García A., Moreno A. T., Use of speed profile as surrogate measure: Effect of traffic calming devices on crosstown road safety performance, Accident analysis and prevention Vol. 61, 2013.

[28] Bohatkiewicz J., Biernacki S., Jamrozik K., Impact of implementation of traffic calming measures on transportation noise in cities, Metody ochrony środowiska przed hałasem - teoria i praktyka, Zakopane 2013.

[29] Ahn K. Rakha H., A field evaluation case study of the environmental and energy impacts of traffic calming, Transportation Research Part D: Transport and Environment, Vol. 14, Issue 6, 2009.

[30] Ainge M., Boutler P. G., Latham S., Driving cycles for measuring passenger car emissions on roads with traffic calming measures, The Science of the total environment 235, 1999. 
[31] Ghafghazi G., Hatzopoulou M., Simulating the environmental effects of isolated and area-wide traffic calming schemes using traffic simulation and microscopic emission modeling, Transportation, Springer 2014.

[32] Lee G., Choi K., Joo S., Oh C., An evaluation framework for traffic calming measures in residential areas, Transportation Research Part D: Transport and Environment Vol. 25, 2013.

[33] Bella F., Driving simulator for speed research on two-lane rural roads, Accident analysis and prevention Vol. 40, 2008.

[34] Antonson H., Blomqvist G., Mårdh S., Wiklund M., Effect of surrounding landscape on driving behaviour: A driving simulator study, Journal of Environmental Psychology, Vol. 29, 2009.

[35] Bergeron J., Thiffault P., Monotony of road environment and driver fatigue: a simulator study, Accident analysis and prevention, Vol. 35, 2003.

[36] Edquist J., Lenné M. G., Rudin-Brown C. M., The effects of on-street parking and road environment visual complexity on travel speed and reaction time, Accident analysis and prevention Vol. 45, 2012.

[37] Charlton S. G., The role of attention in horizontal curves: a comparison of advance warning, delineation, and road marking treatments, Accident analysis and prevention Vol. 39, 2007.

[38] Auberlet J.-M., Bertrand J., Plainchault P., Rosey F., Impact of perceptual treatments on lateral control during driving on crest vertical curves: a driving simulator study, Accident analysis and prevention Vol. 40, 2008.

[39] Ariën C., Brijs K., Brijs T., Daniels S., Jongen E. M. M., Wets G., A simulator study on the impact of traffic calming measures in urban areas on driving behavior and workload, Accident analysis and prevention, 2013.

[40] Ariën C., Brijs K., Brijs T., Ceulemans W., Daniels S., Jongen E. M. M., Vanroelen G., Wets G., Does the effect of traffic calming measures endure over time? - A simulator study on the influence of gates, Transportation Research Part F: Traffic Psychology and Behaviour, Vol. 22, 2014.

[41] Galante F., Guglielmo M. L., Lamberti R., Montella A., Perceptual Measures and Physical Devices for Traffic Calming Along a Rural Highway Crossing a Small Urban Community: Speed Behavior Evaluation in a Driving Simulator, TRB Annual Meeting 2009.

[42] Montella A., Aria M., D'Ambrosio A., Galante F., Mauriello F., Pernetti M., Traffic calming along rural highways crossing small urban communities: driving simulator experiment, Accident analysis and prevention, 2010.

[43] Montella A., Aria M., D’Ambrosio A., Galante F., Mauriello F., Pernetti M., Perceptual Measures to Influence Operating Speeds and Reduce Crashes at Rural Intersections : Driving Simulator Experiment, TRB Annual Meeting 2010.

[44] Montella A., Aria M., D’Ambrosio A., Galante F., Mauriello F., Pernetti M., Simulator evaluation of drivers' speed, deceleration and lateral 
position at rural intersections in relation to different perceptual cues. Accident analysis and prevention Vol. 43, 2011.

[45] Molino J. A., Hermosillo M. B., Katz B. J., Simulator Evaluation of Low Cost Safety Improvements on Rural, Two-Lane, Undivided Roads: Nighttime Delineation for Curves and Traffic Calming for Small Towns, TRB Annual Meeting 2010.

[46] Jamson H., Jamson S., Lai F., Driving simulators for robust comparisons: a case study evaluating road safety engineering treatments, Accident analysis and prevention Vol. 42, 2010.

[47] Corkle J., Giese J. L., Marti M. M., Investigating the Effectiveness of Traffic Calming Strategies on Driver Behavior, Traffic Flow and Speed, Minnesota Department of Transportation 2001. 